\title{
Aloe emodin suppresses EGF-induced neoplastic cell transformation by inhibiting the ERK/MSK1 and AKT/GSK3ß signaling pathways
}

\author{
JUAN ZHANG ${ }^{1}$, LIHUA GUO ${ }^{2}$, QUANWU ZHANG ${ }^{1},{\text { KANGDONG } \text { LIU }^{3} \text { and ZIMING DONG }}^{3}$ \\ ${ }^{1}$ Department of Pathology, Zhengzhou Central Hospital Affiliated to Zhengzhou University; \\ ${ }^{2}$ Department of Pediatric Surgery, The First Affiliated Hospital of Zhengzhou University; \\ ${ }^{3}$ School of Basic Medical Sciences, Zhengzhou University, Zhengzhou, Henan 450052, P.R. China
}

Received March 1, 2017; Accepted November 6, 2017

DOI: $10.3892 / \mathrm{mmr} .2018 .9517$

\begin{abstract}
Natural compounds which can block cell transformation due to potential for chemoprevention have received increased attention. The present study aimed to investigate whether aloe emodin, which is present in aloe latex or the roots of the Rheum palmatum L. are able to block epidermal growth factor (EGF)- and tissue plasminogen activator-induced JB6 C141 cell transformation. The aloe emodin treatment was applied to the JB6 C141 cell neoplastic model. The toxicity of aloe emodin was determined. The present study detected the expression level of AKT serine/threonine kinase 1 (AKT), lysine-tRNA ligase MSK1 (MSK1) and cyclin D1 using western blotting. The cell proliferation and cell cycle distribution were also monitored. And when 95-maximal effective dose ranged between 1 and $15 \mu \mathrm{M}$, the cell death was evident. Aloe emodin-treated cells had an impaired anchorage-independent growth capability, leading to a dose-dependent reduction of colony formation. Western blotting revealed that aloe emodin had a significant effect on phosphorylation of pyruvate dehydrogenase kinase 1 and glycogen synthase kinase $3 \beta$ (GSK3 $\beta$ ) and AKT was inhibited. The present study determined that the proliferation of JB6 C141 cells was reduced in a dose-dependent manner and the effect may be associated with its inhibition of the G1/S cell cycle transition. Cyclin D1 transcriptional activity was reduced to $25 \%, 24 \mathrm{~h}$ following aloe emodin treatment. The protein expression of cyclin D1 was inhibited. The findings of the present study indicated that aloe emodin may be able to suppress neoplastic cell transformation by
\end{abstract}

Correspondence to: Dr Ziming Dong or Dr Kangdong Liu, School of Basic Medical Sciences, Zhengzhou University, 100 Science Avenue, Zhengzhou, Henan 450052, P.R. China

E-mail: zimingdong123@sina.com

E-mail: kangdongliu123@sina.com

Key words: aloe emodin, extracellular signal-regulated kinase, AKT serine/threonine kinase 1 , cell transformation, chemoprevention inhibiting the extracellular-signal regulated kinase/MSK1 and AKT/GSK3 $\beta$ signaling pathways. It may be a potential natural compound for chemoprevention.

\section{Introduction}

Previous studies indicated that epidermal growth factor receptor (EGFR) as a cell membrane growth factor receptor has a crucial role in controlling the key cellular transduction pathways in cancerous cells $(1,2)$. The AKT serine/threonine kinase 1 (AKT)/glycogen synthase kinase $3 \beta$ (GSK3 $\beta$ ) and the extracellular signal-regulated kinase (ERK)/lysine-tRNA ligase MSK1 (MSK1) signaling pathways are the two important downstream signaling pathways of EGFR, which have essential roles in tumor development. Previous studies confirmed this report (3-5). Previous studies indicated that ERK, MSKs, AKT and GSK $3 \beta$ are all critical signal transducers of oncogenic signals in various human tumors (6-8). For example, AKT may be activated through phosphorylation in Ser473 and Thr308 and active AKT may subsequently phosphorylate GSK3 $\beta$ (Ser9) (9). Previous studies revealed that selective GSK3 inhibitors and GSK $3 \beta$ small interfering RNA attenuated tetrandrine-induced G1 type GSK3 $\beta$ that may lead to G1 arrest and apoptosis via cyclin D1 downregulation $(10,11)$. Overexpression of cyclin D1 may promote the development of malignant tumors, such as parathyroid adenoma, breast cancer, colon cancer, lymphoma, melanoma and prostate cancer (12-16). Therefore, the present study investigated whether a natural compound may alter the EGF/ERK/MSK1 and EGF/AKT/GSK3 $\beta$ signaling pathways to prevent EGF-induced JB6 C141 transformation and proliferation.

Aloe emodin is one of the primary components in Rhei Rhizoma. It may be found in aloe and the roots of Rheum, with a molecular formula is $\mathrm{C}_{15} \mathrm{H}_{10} \mathrm{O}_{5}$ (11). Previous studies revealed that aloe emodin has anti-tumor, anti-bacterial, cell-restoring and laxative function (17). A previous study reported that aloe emodin may selectively inhibit human neuroectodermal tumor cell growth and had little acute or chronic toxicity in animal model (18). It inhibited proliferation and anchorage-independent growth of PC3 cells (8). The present study determined that aloe emodin was able to inhibit 
proliferation and transformation of the EGF-induced JB6 C141 cells. Protein content analysis and vitro kinase western blot analysis revealed that aloe-emodin inhibited the ERK/MSK1 and AKT/GSK $3 \beta$ signaling pathways, specifically expression levels of MSK1 and phosphorylation-AKT (Ser473) were markedly inhibited. Phosphorylation of cyclin D1 significantly decreased and large proportion of JB6 C141 cells was arrested at the G1/S phase. Therefore, these findings demonstrated that the EGF/ERK/MSK1 and EGF/AKT/GSK3 $\beta$ signaling pathways may contribute to the suppression proliferation and transformation of EGF-induced JB6 C141 cells, whereas aloe emodin suppressed EGF-induced neoplastic cell transformation and proliferation. Therefore, aloe emodin may be a useful chemoprevention drug for cancer treatment.

\section{Materials and methods}

Materials. Aloe emodin with purity $>95 \%$ and other chemical reagents, including Tris, $\mathrm{NaCl}$ and $\mathrm{SDS}$, were purchased from Sigma-Aldrich (Merck KGaA, Darmstadt, Germany) for molecular biology and buffer preparation. Antibodies for western blot analysis were purchased from Cell Signaling Technology, Inc. (Beverly, MA, USA), Santa Cruz Biotechnology Inc. (Dallas, TX, USA) or Upstate Biotechnology (EMD Millipore, Billerica, MA, USA).

Cell culture. JB6 C141 cells were purchased from American Type Culture Collection (ATCC; Manassas, VA, USA). JB6 C141 cells were propagated in F-12K medium (Cellgro; Corning, Inc., Corning, NY, USA), containing 10\% fetal bovine serum (FBS; Gibco; Thermo Fisher Scientific, Inc.), $100 \mathrm{U} / \mathrm{ml}$ penicillin and $100 \mu \mathrm{g} / \mathrm{ml}$ streptomycin (Cellgro; Corning, Inc.), in a $37^{\circ} \mathrm{C}$ humidified incubator with $5 \% \mathrm{CO}_{2}$. JB6 C141 cells were cytogenetically tested and authenticated prior being frozen. Enough frozen vials were available to ensure that all cell-based experiments could be conducted. Every vial of frozen cells was thawed and maintained in culturing for a maximum of 8 weeks.

EGF or TPA-induced cell transformation. Cells $\left(8 \times 10^{3} / \mathrm{ml}\right)$ were exposed to EGF $(0.1-10 \mathrm{ng} / \mathrm{ml})$ or TPA $(2-20 \mathrm{ng} / \mathrm{ml})$ in $1 \mathrm{ml}$ of $0.33 \%$ basal medium (Sigma-Aldrich; Merck KGaA) containing $10 \% \mathrm{FBS}$. The cultures were maintained in a $37^{\circ} \mathrm{C}$, $5 \% \mathrm{CO}_{2}$ incubator for 10 days (EGF) or 3-4 weeks (TPA), and the cell colonies were scored using a fluorescence microscope (Olympus, Tokyo, Japan) and the Image-Pro PLUS version 4.5 computer software program (Media Cybernetics, Rockville, MD, USA).

Toxicity of aloe emodin. The cytotoxic activity of aloe emodin was detected following exponential cell growth in cell culture medium, which contains $10 \%$ fetal bovine serum (FBS; Gibco; Thermo Fisher Scientific, Inc.), $100 \mathrm{U} / \mathrm{ml}$ penicillin and $100 \mu \mathrm{g} / \mathrm{ml}$ streptomycin (Cellgro; Corning, Inc.) over $48 \mathrm{~h}$ under the conditions listed above. The cells were seeded in 96-well plates for $12 \mathrm{~h}$ prior treatment. Monolayer cells were plated with a density of $1 \times 10^{4}$ cells/well. Aloe emodin (purity $>95 \%$ ) was added to the final experimental concentration and cells were counted after $48 \mathrm{~h}$ using the trypan blue exclusion assay. All of the experiments were conducted in triplicate.
MTS assay. JB6 C141 cells (1x10 cells/well) were seeded into 96-well plates in $100 \mu \mathrm{l} \mathrm{F-12K}$ medium supplemented with $10 \%$ FBS and incubated in a $5 \% \mathrm{CO}_{2}$ incubator with $37^{\circ} \mathrm{C}$. Following culturing for $12 \mathrm{~h}$ with $2.5,5,10,15 \mu \mathrm{M}$ aloe emodin were added to every well. After incubation with $37^{\circ} \mathrm{C}$ for an additional 24, 48, 72 or $96 \mathrm{~h}, 20 \mu \mathrm{l}$ CellTiter96 Aqueous One solution (Promega, Madison, WI, USA) was added to every well. Then cells were cultivated for another $2 \mathrm{~h}$ at $37^{\circ} \mathrm{C}$. Absorbance was quantified at 490 and $690 \mathrm{~nm}$.

Western blotting. For western blot analysis, cells $\left(2 \times 10^{6}\right)$ were cultured in a $10 \mathrm{~cm}$ dish for $24 \mathrm{~h}$. The cells were then treated with $0,2.5,5,10,15 \mu \mathrm{M}$ aloe emodin for $24 \mathrm{~h}$. The proteins were extracted using a lysis buffer, which contains $50 \mathrm{mM}$ Tris (pH 7.4), $150 \mathrm{mM} \mathrm{NaCl}, 1 \%$ NP-40, $0.1 \%$ SDS and was purchased from Sigma-Aldrich (Merck KGaA) and the concentration was determined using the folin-phenol method. A total of $30 \mu \mathrm{g}$ lysate protein per lane was subjected to $10 \%$ SDS-polyacrylamide gel electrophoresis. Following separation, bands were transferred to polyvinylidende difluoride membranes and incubated overnight at $4^{\circ} \mathrm{C}$ with anti-p-ERK (MK12; cat. no. 610030; 1:1,000) and T-ERK (cat. no. $610235,1: 5,000$ ) (both from BD Biosciences San Jose, CA, USA), p-MSK1 (Ser360; cat. no. 9594; 1:1,000; Cell Signaling Technology, Inc., Danvers, MA, USA), T-MSK1 (cat. no. NB120-2562; 1:1,000; Novus Biologicals, LLC, Littleton, CO, USA), p-PDK1 (Ser241; cat. no. 3438S; 1:1,000), T-PDK1 (cat. no. 3062; 1:1,000), p-AKT (cat. no. 9614; 1:1,000), T-AKT (cat. no. 9272; 1:1,000), p-GSK3 (cat. no. 9327; 1:200), T-GSK3 (cat. no. 7265; 1:100) antibodies and $\beta$-actin control antibody (cat. no. 8457; 1:1,000) (all from Cell Signaling Technology, Inc.). Following hybridization with a horseradish peroxidase-conjugated secondary antibody $(1: 2,000$; cat. no. Cor: SE206; Beijing Solarbio Science and Technology Co., Ltd., Beijing, China) for $30 \mathrm{~min}$ at $50^{\circ} \mathrm{C}$, polyvinylidende difluoride membranes were visualized by an enhanced chemiluminescence Detection kit (Amersham Biosciences; GE Healthcare, Chicago, IL, USA).

Anchorage-independent cell growth. Cells were exposed to $0,2.5,5,10,15 \mu \mathrm{M}$ aloe emodin in $1 \mathrm{ml}$ of $0.33 \%$ basal medium (Sigma-Aldrich; Merck KGaA) Eagle's agar containing $10 \%$ FBS. The medium was in a $5 \% \mathrm{CO}_{2}$ incubator at $37^{\circ} \mathrm{C}$ for 14 days and the cell colonies were counted under a fluorescence microscope (Olympus) using Image-Pro Plus version 6.0 (Media Cybernetics, Inc.).

Cell cycle analysis. Cell cycle was analyzed with the Cell Cycle and Apoptosis Analysis kit (Beyotime Institute of Biotechnology, Shanghai, China) following 5 min propidium iodide staining in $37^{\circ} \mathrm{C}$ with a FACSCalibur flow cytometer (Becton-Dickinson, San Jose, CA, USA).

Transfection and luciferase assay. The human cyclin D1 promoter reporter plasmid (1745 CD1 LUC) containing the full-length cyclin D1 gene promoter was provided by RG Pestell (Albert Einstein College of Medicine, Bronx, NY, USA). Transient transfection was performed by using Lipofectamine 2000 (Invitrogen; Thermo Fisher Scientific, Inc., Waltham, MA, USA). Briefly, $6.5 \times 10^{5}$ cells/well were 

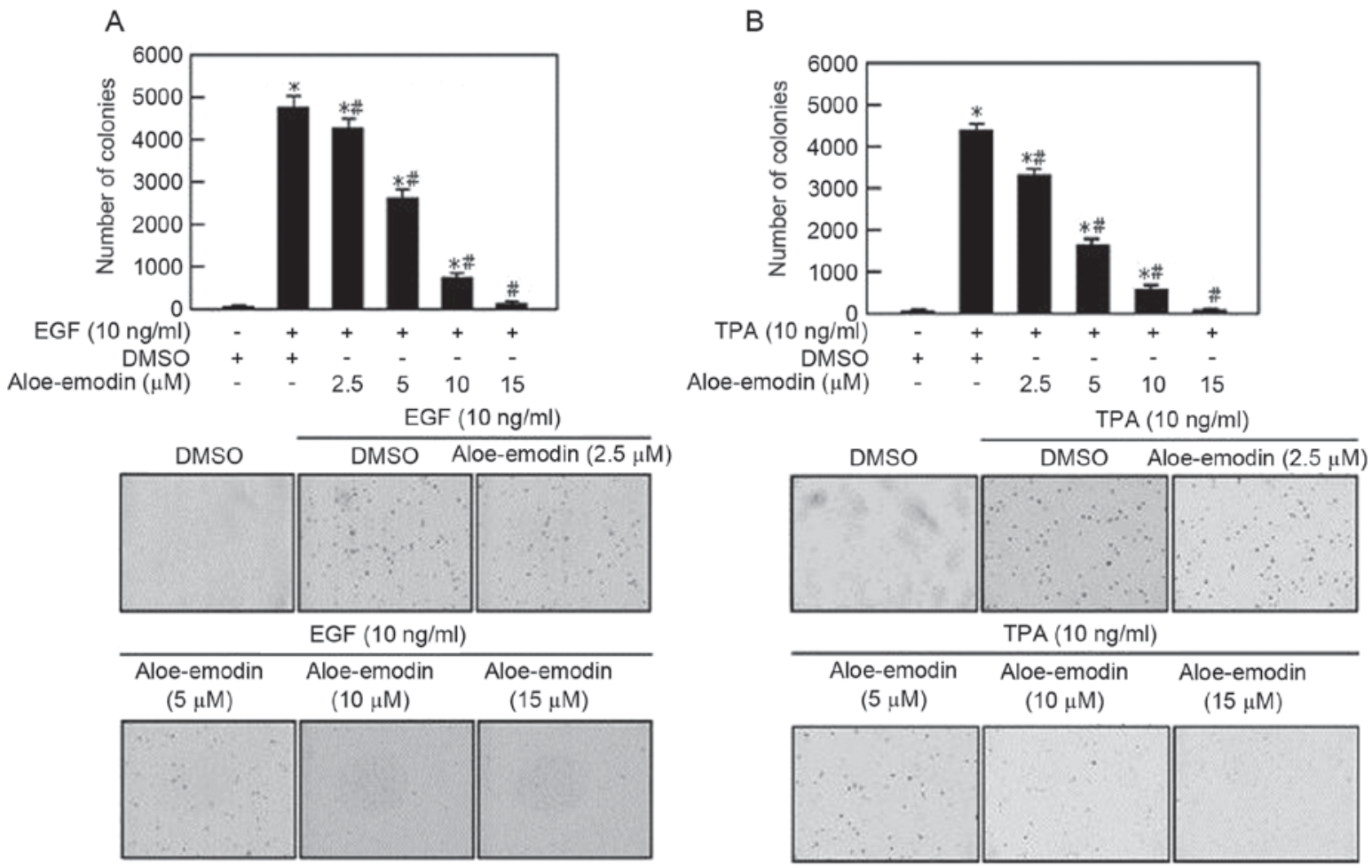

Figure 1. Aloe emodin inhibited EGF- and TPA-induced JB6 C141 transformation. (A) Aloe emodin suppressed anchorage-independent growth of (A) EGF- and (B) TPA-induced JB6 C141 cells. Representative photographs are presented (bottom panels). Colonies were counted and data are presented as the mean \pm standard deviation from three independent experiments. EGF, epidermal growth factor; TPA, tissue plasminogen activator. " $\mathrm{P}<0.05$ vs. DMSO group; ${ }^{*} \mathrm{P}<0.05$ vs. the EGF+DMSO group.

transfected with $1.5 \mu \mathrm{g} \beta$-galactosidase gene (TTP0042 of Thermus thermophilus HB27) for normalization. JB6 C141 cells were cotransfected with the F-12K medium (Cellgro; Corning, Inc., Corning, NY, USA). A protease inhibitor cocktail (Sigma-Aldrich; Merck KGaA) was added to F-12K medium containing FBS $3 \mathrm{~h}$ post-transfection. Cells were incubated for $24 \mathrm{~h}$, lysed with a reporter lysis buffer (Promega) and collected for luciferase assays and P-cyclin D1 activity using a dual-luciferase assay kit (Promega).

Statistical analysis. All quantitative data are expressed as the mean \pm standard deviation. The one-way analysis of variance and Student-Newman-Keuls q test was used for statistical analysis with Statistic Package for Social Science (SPSS 21.0; IBM Corp., Armonk, NY, USA). P<0.05 was considered to indicate a statistically significant difference.

\section{Results}

Cytotoxic activity of aloe emodin. Previous studies determined that aloe emodin may selectively inhibit human tumor cell transformation and growth $(19,20)$. High concentration of aloe emodin may lead to cell death; therefore, it is necessary to identify an appropriate dose to inhibit the tumor cell transformation without cytotoxicity. In the present study, the potential cytotoxicity of aloe-emodin was evaluated on exponentially growing cells at two periods (24 and $48 \mathrm{~h}$ ). As is demonstrated in Fig. 1, aloe-emodin exhbitis a specific dose-dependent cytotoxic effect on EGF- and tissue plasminogen activator (TPA)-induced JB6 C141 cells.
Aloe emodin inhibits EGF and TPA induced JB6 C141 transformation. Cell transformation is a key event of tumorigenesis (21). Aloe emodin exhibited anti-tumor effects against PC3 androgen refractory prostate cells (8). In order to verify whether aloe emodin inhibited cell transformation, the present study examined the effect of aloe emodin on anchorage-independent growth of EGF-induced JB6 C141 cells. Aloe emodin-treated cells had an impaired anchorage-independent growth capability, leading to a dose-dependent reduction in colony formation (Fig. 1A) and TPA-induced JB6 C141 cells were also observed to have reduced colony formation (Fig. 1B).

Aloe emodin inhibits EGF induced MSK and AKT activation. In order to identify the mechanism and molecular target of aloe emodin, the present study treated EGF-induced JB6 C141 cells with various aloe emodin quantities for $24 \mathrm{~h}$. The data indicated that EGF-induced phosphorylation of ERK was not affected by aloe emodin treatment. However, EGF-induced phosphorylation of MSK1 was inhibited by aloe emodin in a dose-dependent manner (Fig. 2A). In addition, aloe emodin could inhibit the phosphorylation of PDK1 and GSK3 $\beta$ (Ser9), which were demonstrated to be upstream and downstream of AKT. Phosphorylated-AKT (Ser473) was inhibited by aloe emodin in a dose-dependent manner. These findings suggested that aloe emodin may inhibit AKT alone or downstream components as opposed to the upstream regulators of EGF-induced PDK1-AKT-GSK3 $\beta$ pathway (Fig. 2B).

Aloe emodin inhibits EGF-induced JB6 C141 cells proliferation in dose-dependent manner and leads to cell 

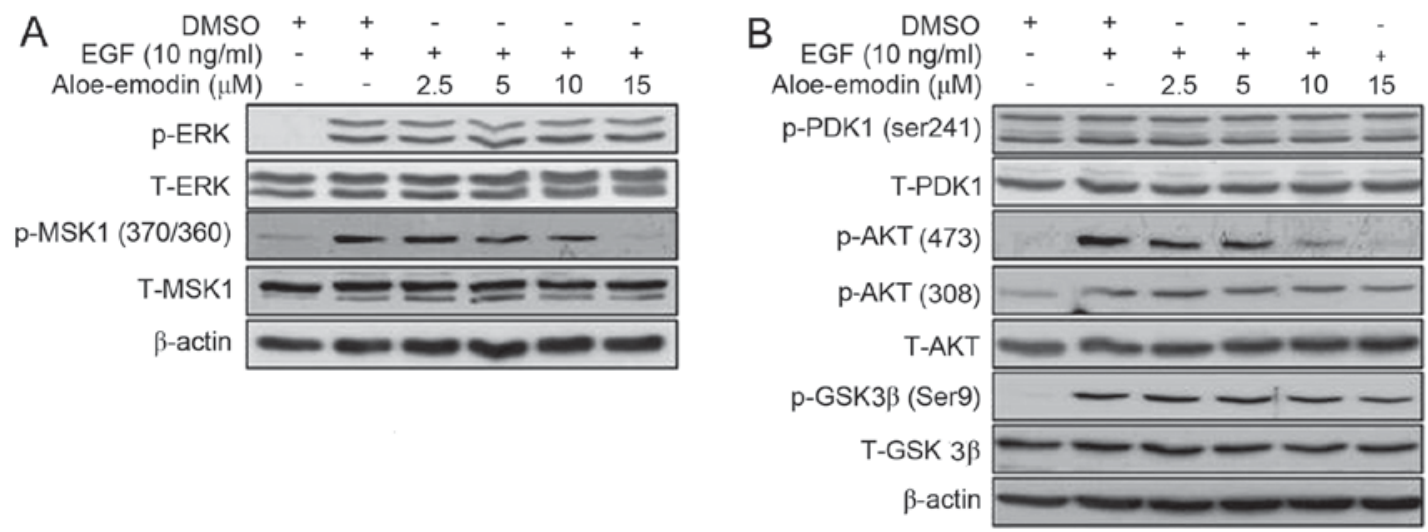

Figure 2. Aloe emodin inhibited EGF-induced MSK1 and AKT activation. EGF-induced JB6 C141 cells were treated for $24 \mathrm{~h}$ with the indicated dose of aloe emodin. The levels of (A) p- and T-ERK, p- and T-MSK1, (B) p- and T-PDK1, p- and T-AKT and p- and T-GSK3 $\beta$ proteins were visualized by western blotting with specific primary and horseradish peroxidase-conjugated secondary antibodies. Every experiment was repeated three times. EGF, epidermal growth factor; p, phosphorylated; T, total; MSK1, lysine-tRNA ligase MSK1; AKT, AKT serine/threonine kinase 1; ERK, extracellular-signal regulated kinase; PDK, pyruvate dehydrogenase kinase 1 ; GSK $3 \beta$, glycogen synthase kinase $3 \beta$.

A

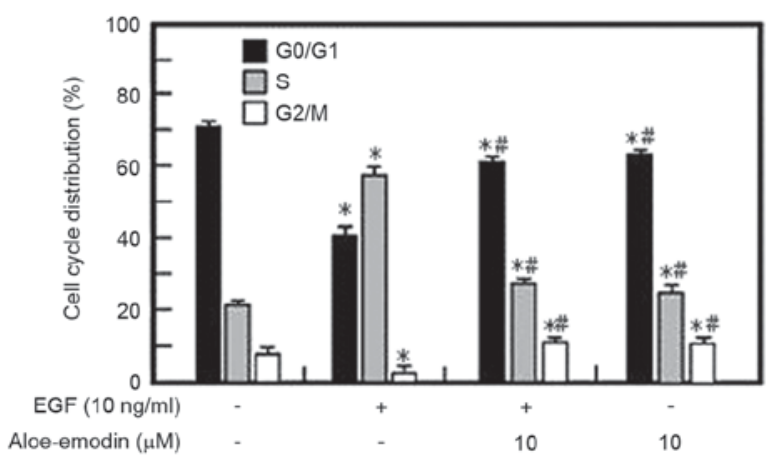

B

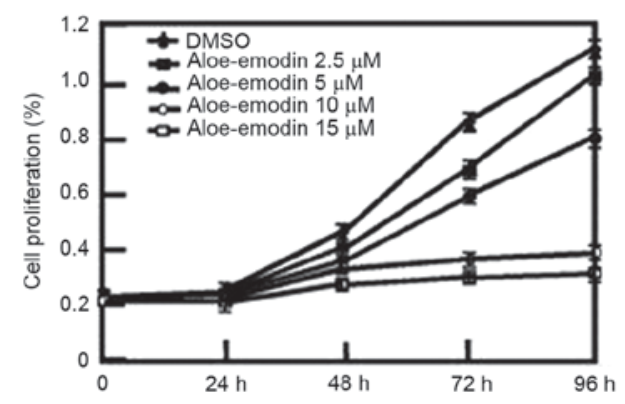

Figure 3. Aloe emodin inhibits EGF-induced JB6 C141 cell proliferation in a dose-dependent manner and leads to a G1 arrest. (A) JB6 C141 cells were treated with EGF and aloe emodin for $18 \mathrm{~h}$ and cell cycle distribution was quantified using flow cytometry with propidium iodide. Data are expressed as the percentage of cells in $\mathrm{G} 1 / \mathrm{G} 0, \mathrm{~S}$, or $\mathrm{G} 2 / \mathrm{M}$ and are presented as the mean \pm standard deviation, from triplicate experiments. Significant change in G0/G1 and S phase cell cycle distribution was observed when compared with the EGF-stimulated group. (B) Aloe emodin inhibited cell proliferation. JB6 C141 cells $\left(1 \times 10^{3}\right.$ cells/well) were treated with the indicated doses of aloe emodin, and proliferation was determined at the indicated time-points using an MTS assay. Data are presented as the mean \pm standard deviation from triplicate independent experiments. EGF, epidermal growth factor. ${ }^{*} \mathrm{P}<0.05$ vs. the control group; ${ }^{~} \mathrm{P}<0.05$ vs. the EGF group.

cycle arrest at the G1 phase. The proliferation and transformation abilities of tumor cells are associated with the cell cycle; therefore, the present study used cell cycle analysis.
The cell cycle distribution of the EGF-induced JB6 C141 cells was analyzed (Fig. 3A). It was revealed that the proliferation of JB6 C141 cells was reduced dose-dependently by aloe emodin treatment (Fig. 3B) and the effect may be associated with its inhibition of the G1/S cell cycle transition (Fig. 3A). Additionally, the present study indicated that aloe emodin inhibited EGF-induced cell transformation in a dose-dependent manner. These findings demonstrated that aloe emodin suppressed the activity of MSK1 and AKT in the ERK/MSK1 and AKT/GSK $3 \beta$ signaling pathways leading to in the suppression of EGF-induced cell proliferation and transformation.

Aloe emodin downregulates the transcriptional activity of cyclin D1 in a dose-dependent manner. Cyclin D1 has an important role in the G1/G0 phase of the cell cycle. The present study determined that aloe emodin may lead to cell cycle arrest at the G1 phase. In order to determine whether aloe emodin modulated the EGF-inducing transcriptional activity of cyclin D1, reporter gene assay was conducted with EGF-inducing JB6 C141 cells (Fig. 4). In this assay, EGF-induced JB6 C141 cells were transiently transfected with plasmids encoding luciferase-driven by a promoter containing cyclin D1 sites, and treated with aloe emodin at 2.5-15 $\mu \mathrm{mol} / 1$. The present study revealed that aloe emodin reduced the cyclin D1 transcriptional activity in EGF-induced JB6 C141 cells in a dose-dependent manner. After $24 \mathrm{~h}$ of treatment, $10 \mu \mathrm{mol} / 1$ aloe emodin reduced cyclin D1 transcriptional activity to $25 \%$ of that in the DMSO-treated cells. The protein expression level of cyclin D1 was also inhibited in a dose-dependent manner.

\section{Discussion}

Aloe emodin is one of primary components of Rhei Rhizoma and has been used for the treatment of various inflammatory diseases in traditional Chinese medicine. Previous studies have reported that aloe emodin may exhibit antitumor effects, it may be able to selectively inhibit the growth and transformation of human tumor cells $(18,22)$. However, these findings were primarily focused on the effect aloe emodin had on cell 

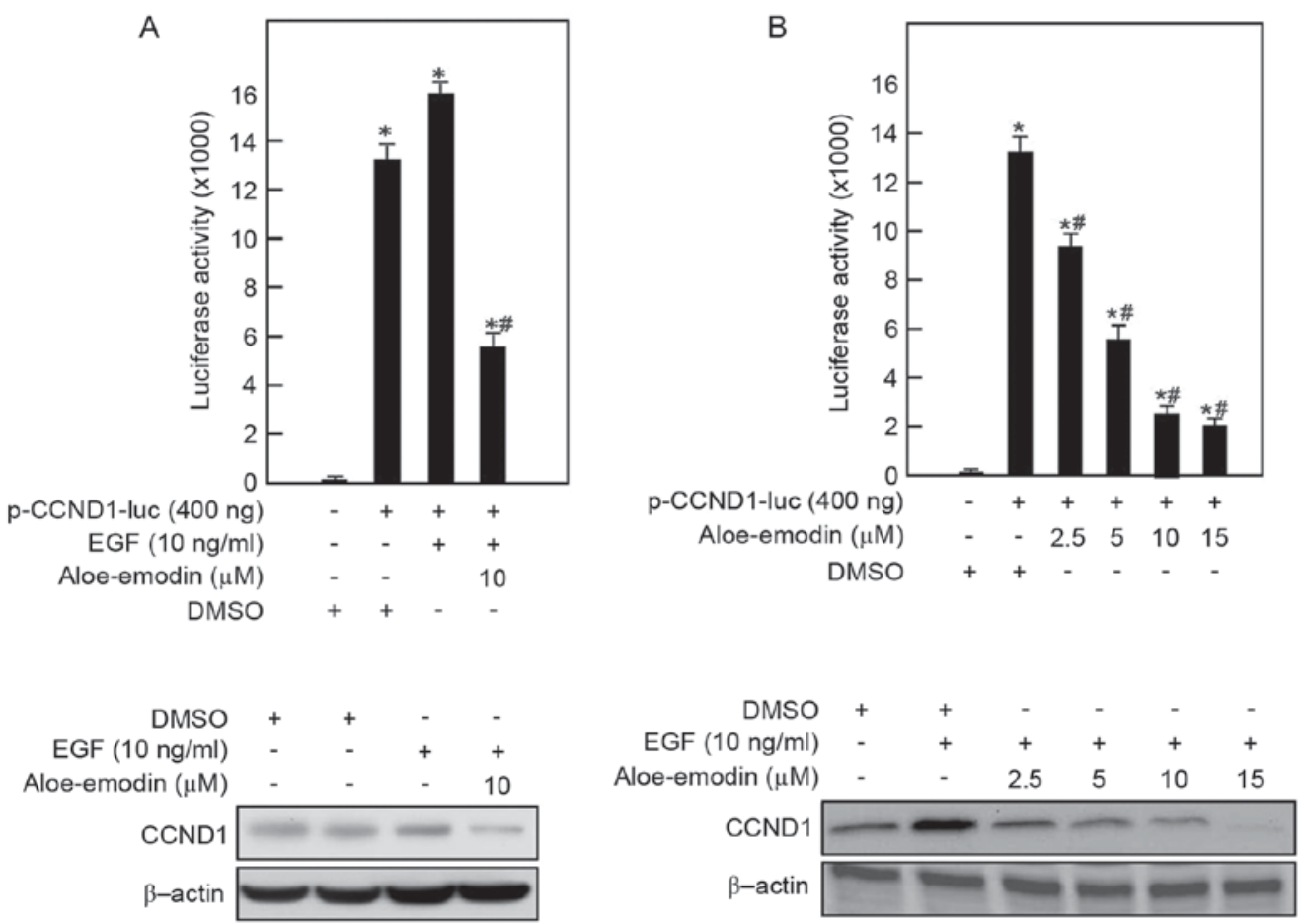

Figure 4. Aloe emodin downregulated the transcriptional activity and protein expression of cyclin D1 in dose-dependent manner. (A) Reporter gene assay was conducted with EGF-induced JB6 C141 cells. In this study, ECF-induced JB6 C141 cells that were treated with DMSO and $10 \mu \mathrm{m} / 1$ aloe emodin for $24 \mathrm{~h}$ were compared and EGF-induced JB6 C141 cells were transiently transfected with luciferase reporter plasmids encoding a promoter containing cyclin D1. The levels of phosphorylated and total proteins were visualized using western blotting with specific primary and horseradish peroxidase-conjugated secondary antibodies. Every experiment was repeated three times. (B) Cells were not exposed to the EGF-induced activation and the concentration of aloe emodin used was at 2.5-15 $\mu \mathrm{mol} / 1$. Every experiment was repeated three times. CCND1, cyclin D1. ${ }^{*} \mathrm{P}<0.05$ vs. the DMSO group; ${ }^{\#} \mathrm{P}<0.05$ vs. the DMSO + p-CCND1-luc group.

proliferation as opposed to the influence of cell transformation. Therefore, the present study used JB6 C141 cells (a common cell transformation model) and treated EGF-induced JB6 C141 cells with different doses of aloe emodin.

The current study determined that aloe emodin may inhibit the EGF-induced or TPA-induced JB6 C141 cell proliferation and anchorage-independent growth (Figs. 1 and 3B). Additionally, it inhibited the cell proliferation and transformation in a dose-dependent manner. Subsequently the present study determined that when the JB6 C141 cells were stimulated with tumor promoters, EGF or TPA, the expression levels of phosphorylated MSK1 and AKT was significantly reduced in a dose-dependent manner following aloe emodin treatment (Fig. 2). The current findings indicated that aloe emodin inhibited cell growth and differentiation by interrupting the ERK/MSK1 and PDK1/AKT/GSK3 $\beta$ signaling pathways. Therefore, ERK/MSK1 and PDK1/AKT/GSK3 $\beta$ signaling pathways may have critical roles in EGF-induced JB6 C141 cell transformation and proliferation. Previous studies revealed that the ERK/MSK1 signaling pathway participated in cell migration and invasion (23), whereas the PDK1/AKT/GSK3 $\beta$ signaling pathway was associated with cell proliferation (24).

In addition, the present study identified that the phosphorylated-AKT (Ser473) and GSK3 $\beta$ (Ser9) were inhibited by aloe emodin treatment in a dose-dependent manner (Fig. 2). Therefore, the present study hypothesized that a reduction of the phosphorylation-AKT (Ser473) may downregulate the activation of GSK $3 \beta$ (Ser9).
Furthermore, proliferation was inhibited by $10 \mu \mathrm{mol} / 1$ aloe emodin when compared with the control group. The effect was associated with the impairment of the G0/G1 cell cycle transition which was associated with the PDK1/AKT/GSK3 $\beta$ signaling pathway (25), particularly the cyclin D1 protein (26) (Fig. 3A). The luciferase activity assays revealed that cyclin D1 transcription was suppressed by aloe emodin treatment in EGF-induced JB6 C141 cells (Fig. 4). The proliferation of EGF-induced JB6 C141 cells was reduced in a dose-dependent manner by aloe emodin treatment (Fig. 3B). A previous study concluded that the reduction of cyclin D1 may arrest the cell cycle in the G2/M phase (16). However, the present study revealed that lower concentrations of aloe emodin had the same effect. Therefore aloe emodin treatment may lead to G0/G1 cell cycle arrest when used in small doses.

Subsequently, the present study focused on the inhibitory mechanism of aloe emodin. Aloe emodin treatment may lead to in the dephosphorylation-AKT (Ser473), inhibition of GSK3 $\beta$ (Ser9), and effectively limit cyclin D1 degradation. A previous study indicated that the AKT/GSK3 $\beta$ signaling pathway had an important role in regulating the expression of cyclin D1 (27). However, the downstream regulators of GSK3 $\beta$ activating cyclin D1 remain to be elucidated.

In conclusion, the present study demonstrated that aloe emodin effectively suppressed transformation and proliferation in a small dose by inhibiting AKT and MSK1 activity. Aloe emodin was able to inhibit the transcriptional activity of cyclin D1 by suppressing the EGF/AKT/GSK $3 \beta$ signaling pathway. These findings revealed that aloe emodin may be 
a potential natural chemopreventive compound for human tumors.

\section{References}

1. Yewale C, Baradia D, Vhora I, Patil S and Misra A: Epidermal growth factor receptor targeting in cancer: A review of trends and strategies. Biomaterials 34: 8690-8707, 2013.

2. Mitsudomi T and Yatabe Y: Epidermal growth factor receptor in relation to tumor development: EGFR gene and cancer. Febs J 277: 301-308, 2010.

3. Drobic B, Espino PS and Davie JR: Mitogen- and stress-activated protein kinase 1 activity and histone $\mathrm{h} 3$ phosphorylation in oncogene-transformed mouse fibroblasts. Cancer Res 64: 9076-9079, 2004

4. Vermeulen L, Vanden Berghe W, Beck IM, Bosscher K and Haegeman G: The versatile role of MSKs in transcriptional regulation. Trends Biochem Sci 34: 311-318, 2009.

5. Seshacharyulu P, Ponnusamy MP, Haridas D, Jain M, Ganti AK and Batra SK: Targeting the EGFR signaling pathway in cancer therapy. Expert Opin Ther Targets 16: 15-31, 2012.

6. Chang S, Iversen L, Kragballe K, Arthur JS and Johansen C: Mice lacking MSK1 and MSK2 show reduced skin tumor development in a two-stage chemical carcinogenesis model. Cancer Invest 29: 240-245, 2011

7. Pérez-Cadahía B, Drobic B, Espino PS, He S, Mandal S, Healy S and Davie JR: Role of MSK1 in the malignant phenotype of Ras-transformed mouse fibroblasts. J Biol Chem 286: 42-49, 2011

8. Liu K, Park C, Li S, Lee KW, Liu H, He L, Soung NK, Ahn JS, Bode AM, Dong Z, et al: Aloe emodin suppresses prostate cancer by targeting the mTOR complex 2 . Carcinogenesis 33 : 1406-1411, 2012

9. Chen XL, Ren KH, He HW and Shao RG: Involvement of $\mathrm{PI} 3 \mathrm{~K} / \mathrm{AKT} / \mathrm{GSK} 3$ beta pathway in tetrandrine-induced G1 arrest and apoptosis. Cancer Biol Ther 7: 1073-1078, 2008.

10. Vermeulen K, Van Bockstaele DR and Berneman ZN: The cell cycle: A review of regulation, deregulation and therapeutic targets in cancer. Cell Prolif 36: 131-149, 2003.

11. Chen MJ, Cheng AC, Lee MF and Hsu YC: Simvastatin induces G1 arrest by up-regulating GSK3beta and down-regulating CDK4/cyclin D1 and CDK2/cyclin E1 in human primary colorectal cancer cells. J Cell Physiol, Aug 18, 2017. doi: 10.1002/jcp.26156 (Epub ahead of print).

12. Sutherland RL and Musgrove EA: Cyclin D1 and mammary carcinoma: New insights from transgenic mouse models. Breast Cancer Res 4: 14-17, 2002.

13. Pecere T, Sarinella F, Salata C, Gatto B, Bet A, Dalla Vecchia F, Diaspro A, Carli M, Palumbo M and Palù G: Involvement of p53 in specific anti-neuroectodermal tumor activity of aloe emodin. Int J Cancer 10: 836-847, 2003.

14. Knudsen KE, Diehl JA, Haiman CA and Knudsen ES: Cyclin D1: polymorphism, aberrant splicing and cancer risk. Oncogene 25: 1620-1628, 2006.
15. Hao L and ElShamy WM: BRCA1-IRIS activates cyclin D1 expression in breast cancer cells by downregulating the JNK phosphatase DUSP3/VHR. Int J Cancer 121: 39-46, 2007.

16. Deharvengt SJ, Gunn JR, Pickett SB and Korc M: Intratumoral delivery of shRNA targeting cyclin D1 attenuates pancreatic cancer growth. Cancer Gene Ther 17: 325-333, 2010

17. Chen R, Zhang J, Hu Y, Wang S, Chen M and Wang Y: Potential antineoplastic effects of Aloe-emodin: A comprehensive review. Am J Chin Med 42: 275-288, 2014

18. Woo SW, Nan JX, Lee SH, Park EJ, Zhao YZ and Sohn DH: Aloe emodin suppresses myofibroblastic differentiation of rat hepatic stellate cells in primary culture. Pharmacol Toxicol 90: 193-198, 2002.

19. Chiu TH, Lai WW, Hsia TC, Yang JS, Lai TY, Wu PP, Ma CY, Yeh CC, Ho CC, Lu HF, et al: Aloe-emodin induces cell death through S-phase arrest and caspase-dependent pathways in human tongue squamous cancer SCC- 4 cells. Anticancer Res 29: 4503-4511, 2009

20. Huang PH, Huang CY, Chen MC, Lee YT, Yue CH, Wang HY and Lin H: Emodin and aloe-emodin suppress breast cancer cell proliferation through ER $\alpha$ inhibition. Evid Based Complement Alternat Med 2013: 376123, 2013.

21. Guo J, Xiao B, Zhang S, Liu D, Liao Y and Sun Q: Growth inhibitory effects of gastric cancer cells with an increase in $S$ phase and alkaline phosphatase activity repression by aloe emodin. Cancer Biol Ther 6: 85-88, 2007.

22. Kang SC, Lee CM, Choung ES, Bak JP, Bae JJ, Yoo HS, Kwak JH and Zee OP: Anti-proliferative effects of estrogen receptor-modulating compounds isolated from Rheum palmatum. Arch Pharm Res 31: 722-726, 2008.

23. Lee CJ, Lee MH, Yoo SM, Choi KI, Song JH, Jang JH, Oh SR, Ryu HW, Lee HS, Surh YJ and Cho YY: Magnolin inhibits cell migration and invasion by targeting the ERKs/RSK2 signaling pathway. BMC Cancer 15: 576, 2013.

24. Zhang Q, Yan HB, Wang J, Cui SJ, Wang XQ, Jiang YH, Feng L, Yang PY and Liu F: Chromatin remodeling gene AT-rich interactive domain-containing protein $1 \mathrm{~A}$ suppresses gastric cancer cell proliferation by targeting PIK3CA and PDK1. Oncotarget 7: 46127-46141, 2016.

25. Vadlakonda L, Pasupuleti M and Pallu R: Role of PI3K-AKT-mTOR and Wnt signaling pathways in transition of G1-S phase of cell cycle in cancer cells. Front Oncol 3: 85, 2013.

26. Hinz M, Krappmann D, Eichten A, Heder A, Scheidereit C and Strauss M: NF-kappaB function in growth control: Regulation of cyclin D1 expression and G0/G1-to-S-phase transition. Mol Cell Biol 19: 2690-2698, 1999.

27. Lai SS, Zhao DD, Cao P, Lu K, Luo OY, Chen WB, Liu J, Jiang EZ, Yu ZH, Lee G, et al: PP2Ac $\alpha$ positively regulates the termination of liverregeneration in mice through the AKT/GSK3 $\beta /$ Cyclin D1pathway. J Hepatol 64: 352-360, 2012. 